\title{
An Update of Helicobacter pylori Prevalence and Associated Risk Factors in Southern Iran: A Population- Based Study
}

\author{
Fateme Ziyaee, MD²; Abdolvahab Alborzi, MD²; Gholamreza Pouladfar, MD²*; Bahman Pourabbas, PhD²; Sadaf Asaee, MSc²; Sareh Roosta, \\ MSc, $\mathbf{M A}^{3}$ \\ ${ }^{1}$ Department of Pediatrics, School of Medicine, Shiraz University of Medical Sciences, Shiraz, Iran \\ ${ }^{2}$ Professor Alborzi Clinical Microbiology Research Center, Shiraz University of Medical Sciences, Shiraz, Iran \\ ${ }^{3}$ Otolaryngology Research Center, Department of Otolaryngology, Shiraz University of Medical Sciences, Shiraz, Iran
}

\begin{abstract}
Background: The childhood period is considered to be the primary period for acquisition of the Helicobacter pylori. The high prevalence rates from developing countries are associated with gastric cancer. A decreasing trend of its prevalence has been reported from different parts of the world. Determining the prevalence rate could be important in choosing preventive strategies. This study aimed to determine the prevalence of $H$. pylori among a group of children from southern Iran to provide an update on the current status of the disease.

Methods: This is a cross-sectional population-based study conducted in Shiraz, southern Iran, from January 2014 to December 2015. Four groups including neonates, children aged 6 months to 3 years, 10- and 15-year-old children were included. Multimonoclonal stool antibody test was used for diagnosis.

Results: Among 436 participants, $24.8 \%$ (95\% Cl: 20.8-29.1) had a positive test for H. pylori: $25 \%$ in neonates $(95 \% \mathrm{Cl}: 16.2-$ $36.1), 22 \%$ in children aged 6 months to 3 years (95\% Cl: $15.2-30.2), 19.5 \%$ in the 10 -year-old (95\% Cl: $12.3-29.4)$, and $29.2 \%$ in 15-year-old children (95\% Cl: 21-39). Sex, age, number of siblings, owning a pet, parents' smoking status, parental education, residential area, birth weight, and feeding status were not found to be statistically significant predictors of $H$. pylori antigen positivity $(P>0.05)$.

Conclusion: The prevalence of H. pylori was estimated to be low in southern Iran in comparison with previous reports or other developing countries. Preventive strategies with respect to low prevalence rates may be considered in the childhood period.

Keywords: Helicobacter pylori, Iran, Monoclonal antibodies, Prevalence

Cite this article as: Ziyaee F, Alborzi A, Pouladfar G, Pourabbas B, Asaee S, Roosta S. An update of Helicobacter pylori prevalence and associated risk factors in southern Iran: a population-based study. Arch Iran Med. 2020;23(10):665-671. doi: 10.34172/ aim.2020.84.
\end{abstract}

Received: March 2, 2019, Accepted: April 13, 2020, ePublished: October 1, 2020

\section{Introduction}

It is estimated that more than $50 \%$ of the global population is infected with Helicobacter pylori. ${ }^{1}$ The prevalence is higher in developing compared with developed countries. ${ }^{2}$ The highest prevalence rate is in South America and Asia. ${ }^{3}$ Also, high prevalence rates of $H$. pylori infection have been reported from different parts of Iran. In Shiraz, southern Iran, in 2006 , the prevalence rate ranged $57 \%$ to $98 \%$ in children from different age groups according to the stool antigen test (SAT). ${ }^{4}$ In another study in Rasht, northern Iran, in 2007, the prevalence of infection in high school children was reported to be $40 \%$ using the SAT. ${ }^{5}$

The bacterium, although mostly asymptomatic, is associated with some upper gastrointestinal and extraintestinal diseases including lymphoma of the mucosa, chronic gastritis, peptic ulcers, iron deficiency anemia, vitamin B12 deficiency and most importantly, gastric carcinoma. ${ }^{6,7}$ Among risk factors of the coronary artery diseases, hyperlipidemia is associated with $H$. pylori. $^{8}$ Specifically in the Iranian population, gastric cancer has been strongly associated with diet and $H$. pylori infection. ${ }^{9}$

The childhood period is considered to be the primary period for acquisition of $H$. pylori infection. ${ }^{9,10}$ It has been suggested that screening for $H$. pylori infection and precancerous lesions may serve as a preventive strategy against the development of gastric adenocarcinoma. ${ }^{11}$ A few guidelines on $H$. pylori infection from around the world indicate that eradication of $H$. pylori would result in reduction of the incidence of gastroduodenal diseases, including gastric cancer, and would decrease new infections in future generations. ${ }^{12-14}$ Based on these guidelines, Japan health insurance systems approved the coverage of the diagnosis and eradication of $H$. pylori in all infected patients. ${ }^{12,15}$ In order to develop a preventive strategy, evaluation of $H$. pylori prevalence is important. SATs are noninvasive and inexpensive diagnostic tests 
for $H$. pylori infection. ${ }^{12}$ Early SATs used an enzyme immunoassay (EIA), based on polyclonal antibodies. While they provided reliable results for the diagnosis of $H$. pylori infection, controversial results were sometimes observed in post-eradication assessment due to false positives. ${ }^{16,17}$

Monoclonal antibody-based techniques generally have higher specificity. SATs based on monoclonal antibodies have been developed and found to be more accurate than those using polyclonal antibodies. ${ }^{18}$ A meta-analysis also showed that the specificity of SATs based on monoclonal antibodies was 0.97 (95\% CI: 0.96-0.98). ${ }^{19}$ Monoclonal antibody-based enzyme-linked immunosorbent assays (ELISA) have provided a non-invasive tool for the evaluation of bacterial colonization in the pediatric population with sensitivity and specificity of more than $85 \%$ and $90 \%$, respectively, compared with UBT, culture or histology. ${ }^{20-22}$

In this study, we evaluated the prevalence of $H$. pylori and its associated factors among a group of children from southern Iran, in order to determine changes in the infection trend and to provide an update on the current condition of the disease. Our study also included neonates which provided a more comprehensive assessment of the pediatric population. In addition, we used multiple monoclonal assays, which have high accuracy.

Regarding the worldwide epidemiology of $H$. pylori in the pediatric population, infection rates vary from $4.9 \%{ }^{23,24}$ to $73.3 \%$ in a group of children from Kenya. ${ }^{25}$

A study in 2013 found that among 516 children and young adults (12-25 years old) in Belgium, the prevalence of $H$. pylori using UBT was $11 \%(3 \%-60 \%)$ and the most important factor affecting the prevalence was geographical distribution or place of residence. ${ }^{26}$

In 2015, Krueger et al used the augmented data from the National Health and Nutrition Examination Survey (NHANES) from the United States to evaluate the association between a positive serum for $H$. pylori (positive $\mathrm{IgG}$ ) and different factors. In their multivariate analysis, they found that among participants aged 3 to 19 years, increased age, race, crowded housing (persons per room) and lower income were associated with higher rates of $H$. pylori. ${ }^{27}$

\section{Materials and Methods}

Study Protocol

This is a cross-sectional population-based study conducted in Shiraz, Iran, during a 2-year period from January 2014 to December 2015. Data was collected from four different age groups including neonates (younger than 28 days) who visited a phototherapy center and Well Baby unit, children aged 6 months to 3 years who attended kindergartens, 10- and 15-year-old children attending primary schools and high schools, respectively. Children with any gastrointestinal symptoms including diarrhea, abdominal pain, nausea, vomiting and those who used any antibiotics during the two weeks prior to sampling were excluded from the study.

\section{Data Collection}

Shiraz is one of the five largest cities in southern Iran with a population of about 1.5 million. The city is divided in 10 regions. For the first age group (neonates), samples were collected from Hafez hospital affiliated to the Shiraz University of Medical Sciences. In Hafez hospital, women of different socioeconomic status are admitted for delivery. The neonates were selected using simple random sampling from apparently healthy ones. For the rest of the study population, data was collected from all regions to provide heterogeneity in terms of the participants' socio-economic status. Samples were obtained from all ten regions of Shiraz using simple random sampling. A questionnaire was used to obtain demographic data from each individual.

Questions were classified into three parts, namely those related to the child, parents, and region of residence. In the section related to the child, data was gathered on age, sex, birth weight, type of feeding in the neonatal group (breast feeding or formula feeding), route of delivery in the neonatal group (natural vaginal delivery or caesarean section), present or past gastrointestinal symptoms, and antibiotic use in the previous two weeks. In the section related to the parents, data was gathered on parental education, number of children, smoking habits (number of cigarettes per day or using water-pipe), and owning a pet.

Parents were asked to collect stool samples from their children at home and keep it at 2-8 degrees centigrade for a maximum of 72 hours and to bring it to the preselected coordinated centers as soon as possible. Stool samples were transferred daily to the referral lab at Professor Alborzi Clinical Microbiology Research Center, Shiraz, Iran. The samples were then frozen at $-70^{\circ} \mathrm{C}$.

To diagnose $H$. pylori in the stool samples, we used a laboratory-based monoclonal stool antibody test, the Premier Platinum HpSA Plus (HpSA ELISA II; Meridian Diagnostics, Inc., Cincinnati, OH, United States), which uses multiple murine monoclonal antibodies. Testing was done according to the manufacturer's guidelines. The cut-off values for the HpSA EIA defined by optical density at $450 \mathrm{~nm}$ and $450 / 630 \mathrm{~nm}$, were 0.140 , and 0.1 , respectively. This test has a sensitivity of $96.1 \%$ and specificity of $95.7 \%$. Positive and negative predictive values for this test are $96 \% .^{28}$

\section{Definition of Variables}

The regions from which the samples were randomly selected included ten regions from Shiraz. Each region differed from the others in terms of socio-economic conditions.

Educational status was classified as illiterate, high school 
education (diploma) and lower, and university education. Low birth weight in the neonatal group was defined as birth weight under 2500 g. Exclusive breast feeding in the neonatal group was defined as no episode of formula feeding.

\section{Statistical Analysis}

A minimum sample size of 96 children was calculated considering $60 \%$ prevalence, $10 \%$ precision and $95 \%$ confidence interval. Data analysis was done using the SPSS $^{\circledR}$ for Windows ${ }^{\circledR}$, version 20 (SPSS Inc., Chicago, IL, USA).

The association between each qualitative variable and $H$. pylori antigen status was determined using the chi-square and the Fisher's exact tests. A multiple logistic regression analysis was used to evaluate the simultaneous association of variables with $H$. pylori antigen status. Due to the large number of variables for the regression analysis, only those variables with a $P$ value of less than 0.2 in the bivariate comparison between the antigen positive and the antigen negative groups were included in the logistic model with enter method. In the enter method, all the input variables are entered simultaneously. Data are presented as frequencies and percentages, where appropriate. A $P$ value $<0.05$ was considered as statistically significant.

\section{Results}

Overall, 436 participants entered the study, of whom 24.8\% (95\% CI: 20.8-29.1) tested positive for H. pylori in their stool samples. Eighty children were included in the neonatal group, 128 children in the 6 month-3 year old group, 92 in the 10-year-old group and 106 in the 15-year-old group. Evaluating each age group separately showed that $25 \%$ of the neonates (95\% CI: $16.2-36.1$ ), $22 \%$ of the children aged 6 months to 3 years (95\% CI: $15.2-30.2), 19.5 \%$ of those aged 10 years (95\% CI: $12.3-$ 29.4 ) and $29.2 \%$ of those aged 15 years (95\% CI: $21-39$ ), had a positive antigen for $H$. pylori.

None of the variables including sex $(P=0.980)$, age $(P=0.105)$, region of residence $(P=0.153)$, number of siblings $(P=0.275)$, parental education (neither mother's education $(P=0.135)$ nor father's education $(P=0.513))$, owning a pet $(P=0.189)$, parents' smoking status $(P=$ $0.843)$, birth weight $(P=0.443)$ and feeding status $(P$ $=0.981)$ were statistically different between the antigen positive and the antigen negative groups (Table 1).

Multiple logistic regression analysis demonstrated that age $(P=0.226)$, region of residence $(P=0.353)$, owning a pet $(P=0.839)$ and mother's education $(P=$ 0.292) were not significant predictors of $H$. pylori antigen positivity (Table 2). The total sample size and the number of cases (people with a positive test) included in analysis for the model presented in Table 2 were 319 and 77, respectively. According to Concato et $\mathrm{al}^{29}$ and Peduzzi et $\mathrm{al},{ }^{30}$ the minimum sample size based on the rule of event- per-variable of 10 is acceptable for logistic regression. In this study, there were 16 parameters (including the intercept) to be estimated in the logistic regression model presented in Table 2; so, at least 160 cases were required but there were only 107 cases with many missing values for variables according to Table 1 . This lack of data may lead to selection bias and hence, reduced statistical power and precision for modeling. Also, sparse data were evident for some variables in Table 1 including region included in the model (Table 2) and some confidence limits were unrealistically large suggesting "sparse-data bias". ${ }^{31}$

\section{Discussion}

Here, we have studied the prevalence and associated factors of $H$. pylori using multiple monoclonal stool antibodies among different age groups of pediatric participants in southern Iran. We found that the overall prevalence of $H$. pylori was $24.8 \%$, which was the highest among 15 -yearold children (29.2\%). The most interesting findings in our study is probably the significant decrease in $H$. pylori prevalence compared with that reported from Shiraz 10 years ago according to a population-based study which showed an overall prevalence of $82 \% .{ }^{4}$ This shows improvements in diagnostic modalities (decreasing false positive rates), treatment and socio-economic status, especially among the pediatric population.

The number of siblings, parental education and region of residence, as parameters of socioeconomic status, were not associated with a positive antigen test. The prevalence rate in different parts of Shiraz varied from $13.5 \%$ in region 1 to $52.6 \%$ in region 8 , which correlates with socioeconomic condition of these regions. For example, region 1 has moderate to high socioeconomic status but region 8 has low socioeconomic status. Although region 8 , with the highest population density among all the ten regions, also had the highest rate of $H$. pylori prevalence compared with the other nine regions in our study, the impact of region of residence was not statistically significant. Our study included a wide range of geographical areas in Shiraz which provided strong heterogeneity in terms of socio-economic status and distribution of baseline characteristics across the comparison groups.

In the neonatal group, we also studied the association of birth weight, feeding status (breast-fed or formulafed), and route of delivery (natural vaginal delivery or caesarean section) but they were not related to higher prevalence of $H$. pylori. Only few studies have reported the prevalence of $H$. pylori in neonates. In an Italian study from 2002 to 2005 , formula feeding and admission to the NICU was associated with positive SAT in neonates. ${ }^{32}$ In another study in Norway in 2006, route of delivery was an important predictor of $H$. pylori antigen positivity and $59 \%$ of the neonates born through natural vaginal delivery had positive SAT compared with $10 \%$ of the neonates who were born through caesarean section. ${ }^{33}$ 
Table 1. Baseline Characteristics of Participants and Comparison of Antigen-positive and Negative Individuals

\begin{tabular}{|c|c|c|c|c|c|}
\hline \multirow{3}{*}{ Variables } & \multicolumn{4}{|c|}{ Antigen } & \multirow{3}{*}{$P$ value } \\
\hline & \multicolumn{2}{|c|}{ Positive } & \multirow{2}{*}{$\begin{array}{c}\text { Negative } \\
\text { No. }(\%) \\
\end{array}$} & \multirow{2}{*}{ Total } & \\
\hline & No. $(\%)$ & $95 \% \mathrm{Cl}^{*}$ & & & \\
\hline \multicolumn{6}{|l|}{ Sex } \\
\hline Male & $55(51.4)$ & $42.0-60.6$ & 167 (51.5) & 222 & \multirow{3}{*}{0.980} \\
\hline Female & $52(48.6)$ & $39.3-57.9$ & $157(48.5)$ & 209 & \\
\hline Total & 107 & - & 324 & 431 & \\
\hline \multicolumn{6}{|l|}{ Age } \\
\hline 1-28 day & $20(20.6)$ & $13.8-29.7$ & $60(19.4)$ & 80 & \multirow{5}{*}{0.105} \\
\hline $6 \mathrm{~m} / \mathrm{o}-3 \mathrm{y} / \mathrm{o}$ & $28(28.9)$ & $20.8-38.6$ & $100(32.4)$ & 128 & \\
\hline $10 \mathrm{y} / \mathrm{o}$ & 18 (18.5) & $12.1-27.4$ & $74(23.9)$ & 92 & \\
\hline $15 \mathrm{y} / \mathrm{o}$ & $31(32.0)$ & $23.5-41.8$ & $75(24.3)$ & 106 & \\
\hline Total & 97 & - & 309 & 406 & \\
\hline \multicolumn{5}{|c|}{ Region ${ }^{\sharp}$ (80 samples collected from neonates of Hafez hospital are not included) } & \multirow{12}{*}{0.153} \\
\hline 1 & $5(6.5)$ & $2.8-14.3$ & $32(13.2)$ & 37 & \\
\hline 2 & $4(5.2)$ & $2.0-12.6$ & $16(6.6)$ & 20 & \\
\hline 3 & $8(10.4)$ & $5.4-19.2$ & $27(11.2)$ & 35 & \\
\hline 4 & $8(10.4)$ & $5.4-19.2$ & $23(9.5)$ & 31 & \\
\hline 5 & $12(15.6)$ & $9.1-25.3$ & $38(15.7)$ & 50 & \\
\hline 6 & $11(14.3)$ & $8.2-23.8$ & $34(14.0)$ & 45 & \\
\hline 7 & $4(5.2)$ & $2.0-12.6$ & $22(9.1)$ & 26 & \\
\hline 8 & $10(13.0)$ & $7.2-22.3$ & $9(3.7)$ & 19 & \\
\hline 9 & $4(5.2)$ & $2.0-12.6$ & $16(6.6)$ & 20 & \\
\hline 10 & $11(14.3)$ & $8.2-23.8$ & $25(10.3)$ & 36 & \\
\hline Total & 77 & - & 242 & 319 & \\
\hline \multicolumn{5}{|l|}{ Number of siblings } & \multirow{5}{*}{0.275} \\
\hline None & $31(32.3)$ & $23.8-42.2$ & $109(35.5)$ & 140 & \\
\hline One & $34(35.4)$ & $26.6-45.4$ & $128(41.7)$ & 162 & \\
\hline More than one & $31(32.3)$ & $23.8-41.2$ & $70(22.8)$ & 101 & \\
\hline Total & 96 & - & 307 & 403 & \\
\hline \multicolumn{5}{|l|}{ Mother's education } & \multirow{5}{*}{0.135} \\
\hline Illiterate & 11(11.4) & $6.5-19.4$ & $17(5.5)$ & 28 & \\
\hline High school and lower & $57(59.4)$ & $49.4-68.7$ & $195(63.3)$ & 252 & \\
\hline University education & $28(29.2)$ & $21.0-38.9$ & $96(31.2)$ & 124 & \\
\hline Total & 96 & - & 308 & 404 & \\
\hline \multicolumn{5}{|l|}{ Father's education } & \multirow{5}{*}{0.513} \\
\hline Illiterate & $5(5.2)$ & $2.2-11.6$ & 11(3.6) & 16 & \\
\hline High school and lower & $65(67.7)$ & $57.8-76.2$ & $197(64.0)$ & 262 & \\
\hline University education & $26(27.1)$ & $19.2-36.7$ & $100(32.5)$ & 126 & \\
\hline Total & 96 & - & 308 & 404 & \\
\hline Owning a pet & & & & & \\
\hline Yes & $17(17.5)$ & $11.2-26.3$ & $38(12.3)$ & 55 & 180 \\
\hline No & $80(82.5)$ & $73.7-88.8$ & $271(87.7)$ & 351 & 0.189 \\
\hline Total & 97 & - & 309 & 406 & \\
\hline Smoking Parent & & & & & \\
\hline Yes & $21(21.6)$ & $14.6-30.8$ & $64(20.7)$ & 85 & \\
\hline No & $76(78.4)$ & $69.2-85.4$ & $245(79.3)$ & 321 & 0.843 \\
\hline Total & 97 & - & 309 & 406 & \\
\hline Low birth weight & & & & & \\
\hline Yes & $2(12.5)$ & $3.5-36.0$ & $12(21.1)$ & 14 & \\
\hline No & $14(87.5)$ & $64.0-96.5$ & 45 (78.9) & 59 & 0.443 \\
\hline Total & 16 & - & 57 & 73 & \\
\hline Exclusive breast-feeding & & & & & \\
\hline Yes & $14(87.5)$ & $51.2-88.2$ & $50(87.7)$ & 64 & \\
\hline No & $2(12.5)$ & $2.9-31.4$ & $7(12.3)$ & 9 & 0.981 \\
\hline Total & 16 & - & 57 & 73 & \\
\hline
\end{tabular}

y/o, years old; $\mathrm{m} / \mathrm{o}$, months old.

*95\% confidence interval for $\mathrm{H}$. pylori antigen positivity. \#Shiraz (one of the five largest cities in Iran) is divided in 10 regions (in terms of socio-economic conditions) and samples were obtained from all 10 regions using simple random sampling. ${ }^{*}$ Chi-square test. ${ }^{* *}$ Fisher $>$ s exact test. 
Table 2. Multiple Logistic Regression Analysis for Acquiring a Positive Antigen Test for H. pylori

\begin{tabular}{|c|c|c|c|}
\hline Variables & OR & $\begin{array}{l}95 \% \mathrm{Cl} \\
\text { for OR }\end{array}$ & $P$ Value \\
\hline Age & & & 0.505 \\
\hline 1-28 day & 0.93 & $0.51-1.82$ & 0.671 \\
\hline $6 \mathrm{~m} / \mathrm{o}-3 \mathrm{y} / \mathrm{o}$ & 0.86 & $0.42-1.76$ & 0.684 \\
\hline $10 \mathrm{y} / \mathrm{o}$ & 0.56 & $0.26-1.19$ & 0.135 \\
\hline $15 \mathrm{y} / \mathrm{o}$ & Reference & - & - \\
\hline Region* & & & 0.337 \\
\hline 1 & 0.32 & $0.09-1.10$ & 0.072 \\
\hline 2 & 0.56 & $0.14-2.17$ & 0.410 \\
\hline 3 & 0.70 & $0.23-2.15$ & 0.538 \\
\hline 4 & 0.82 & $0.27-2.45$ & 0.723 \\
\hline 5 & 0.72 & $0.26-1.96$ & 0.528 \\
\hline 6 & 0.67 & $0.24-1.88$ & 0.453 \\
\hline 7 & 0.45 & $0.12-1.66$ & 0.233 \\
\hline 8 & 2.69 & $0.68-10.68$ & 0.157 \\
\hline 9 & 0.69 & $0.18-2.66$ & 0.597 \\
\hline 10 & Reference & - & - \\
\hline \multicolumn{4}{|l|}{ Owning a pet } \\
\hline Yes & 1.15 & $0.54-2.46$ & 0.701 \\
\hline No & Reference & - & - \\
\hline Mother's education & & & 0.625 \\
\hline Illiterate & 1.34 & $0.26-6.75$ & 0.718 \\
\hline High school and lower & 0.79 & $0.40-1.52$ & 0.484 \\
\hline University education & Reference & - & - \\
\hline
\end{tabular}

y/o, years old; m/o, months old.

* Shiraz (one of the five largest cities in Iran) is divided in 10 regions (in terms of socio-economic conditions) and samples were obtained from all 10 regions using simple random sampling.

However, in our study, $23 \%$ of the neonates born through natural vaginal delivery had positive SAT compared with $26 \%$ of the neonates who were born through caesarean section. Candida albicans is likely a carrier for H. pylori and colonization of the vagina with Candida albicans is one of the transmission routes of $H$. pylori from mothers to neonates. ${ }^{34}$

In one of the most recent studies in 2007 in northern Iran, 961 children between the ages of 7 to 11 years were evaluated for $H$. pylori SAT using a polyclonal assay. The prevalence of $H$. pylori was found to be $40 \%$ and $43.6 \%$ in the total population and children aged 10-11 years, respectively. ${ }^{5}$ Similar to our study, the number of family members and parents' education were found to be insignificantly associated with $H$. pylori prevalence. We found the prevalence rate of $H$. pylori to be lower among 10 -year-old children (19.5\% compared with $43.6 \%$ in the former study). This could be attributed to multiple factors including the diagnostic kits which were used in the studies, as we used multiple monoclonal based kits which are more accurate than the polyclonal kit which were used in the mentioned study.

In another study which used a polyclonal antibodybased assay in the same city where the current study has been conducted, 593 children from five different age groups were studied during 2006. They found that none of the age groups, including those aged 8-10 months, 2-3 years, 5-6 years and 9-10 years, showed a statistically significant difference regarding $H$. pylori prevalence (83\%, $98 \%, 88 \%$ and $89 \%$, respectively); however, they did find the group aged 14-15 years to have a significantly lower prevalence of $H$. pylori (58\%). ${ }^{4}$ Dissimilarly in this study, none of the age groups showed a significant difference regarding $H$. pylori status.

The diversity in $H$. pylori prevalence recorded in our age groups could be due to the auto-curability and the reinfection phenomena, as some studies have documented annual auto-curability rates to be as high as $5.5 \%$ among the pediatric population. ${ }^{35}$

Similar to previous studies from Iran, we did not find an association between $H$. pylori and sex, age, parents' smoking status and some socio-economic factors including: number of siblings and parental education. Birth weight and type of feeding in the neonatal group were also insignificant predictors of $H$. pylori stool antigen positivity. Compared with other countries, especially those with higher socioeconomic status, we did have higher prevalence rates of H. pylori.

A similar decrease has been recorded in other studies, as well. Bures et al found a significant decrease in $H$. pylori prevalence during a ten-year period from 2001 to 2011 (41.7\% vs. $23.5 \%)$ in the Czech Republic. ${ }^{36}$ After an appropriate socio-economic indexing score is introduced, a more comprehensive understanding of the association between $H$. pylori and socio-economic status will be understood. We propose larger studies in the context of cohort studies that consider multiple socio-economic factors to evaluate the association between these factors and the prevalence of $H$. pylori.

Our study had some strong points and some limitations. One issue with different studies relates to the screening method used for the detection of $H$. pylori. Unlike our study in which we used a multiple monoclonal antibodybased stool ELISA test for the diagnosis of H. pylori, many of the previous studies in the region, as stated before, have used polyclonal antibody-based stool EIA tests. Polyclonal antibody-based stool EIA's have lower specificity than monoclonal antibody-based stool EIA tests ${ }^{13}$ which have a diagnostic accuracy equivalent to that of the UBT which is considered the best test for the diagnosis of $H$. pylori among non-invasive diagnostic tests. ${ }^{37} \mathrm{We}$ did not have a standard index for the evaluation of socio-economic status and different factors related to socio-economic status were separately assessed. Perhaps after a suitable indexing score has been introduced, evaluation of socio-economic status may show a more significant impact on $H$. pylori prevalence. Also, considering the fact that we excluded children who had any gastrointestinal symptoms and those who used any antibiotics during the two weeks prior 
to sampling, the prevalence of $H$. pylori infection may be underestimated because of incidence-prevalence bias. In addition, we were not able to determine the time of acquisition of infection. It may blur etiologic associations (for example, between $H$. pylori infection and low birth weight) because of reverse causality bias. Also, missing data in variables is another limitation of the study which may result in selection bias.

Our study showed that the prevalence of $H$. pylori among the pediatric population in southern Iran had a significant decrease from a decade ago and in some regions, the prevalence is even similar to developed countries. Regarding the difference in prevalence, perhaps the effect of different variables such as age that have been shown to be associated with $H$. pylori in other regions of the world, is highly dependent on geographical area and plays an insignificant role in the prevalence of $H$. pylori among Iranian children.

In developing countries, the preferred method for $H$. pylori management would be prophylactic vaccination. ${ }^{38}$ In 2016, an oral vaccine against the bacterium was used in China for children; after one year of follow-up, it was $71 \%$ effective. ${ }^{39}$ The decrease in the rate of $H$. pylori prevalence in Iran shows that from now on, it would be cost-effective to use a vaccination protocol to prevent the disease and especially its side effects, including gastric cancer.

\section{Authors' Contribution}

PG, PB and MR: Study concept and design. ZF: Data collection. AS: Material preparation. ZF, PG, PB and RS: Acquisition, analysis, or interpretation of data. RS: Statistical analysis. ZF and PG: Drafting of the manuscript. AA and MR: Critical revision of the manuscript for important intellectual content. All authors commented on previous versions of the manuscript. All authors read and approved the final manuscript.

\section{Conflict of Interest Disclosures}

The authors have no conflict of interest to declare regarding the manuscript.

\section{Ethical Statement}

The study protocol was approved by the institutional review board of both Shiraz University of Medical Sciences and the Professor Alborzi Clinical Microbiology Research Center. The study was in accordance with the declaration of Helsinki guidelines. All parents gave their written consent to enter the study.

\section{Acknowledgements}

The authors would like to thank Shiraz University of Medical Sciences for their financial support of the study (grant \#8675), Dr. Nasrin Shokrpour for editorial assistance at the Center for Development of Clinical Research of Nemazee Hospital. This study was extracted from the thesis presented for obtaining the specialty of pediatrics degree by Fateme Ziyaee, MD.

\section{References}

1. Mitchell H, Katelaris P. Epidemiology, clinical impacts and current clinical management of Helicobacter pylori infection. Med J Aust. 2016;204(10):376-80. doi: 10.5694/mja16.00104.

2. Pellicano R, Ribaldone DG, Fagoonee S, Astegiano M, Saracco GM, Mégraud F. A 2016 panorama of Helicobacter pylori infection: key messages for clinicians. Panminerva Med. 2016;58(4):304-17.
3. Pourfarzi F, Whelan A, Kaldor J, Malekzadeh R. The role of diet and other environmental factors in the causation of gastric cancer in Iran--a population based study. Int J Cancer. 2009;125(8):1953-60. doi: 10.1002/ijc.24499.

4. Alborzi A, SoltaniJ, Pourabbas B, Oboodi B, Haghighat M, Hayati $\mathrm{M}$, et al. Prevalence of Helicobacter pylori infection in children (south of Iran). Diagn Microbiol Infect Dis. 2006;54(4):25961. doi:10.1016/j.diagmicrobio.2005.10.012.

5. Mansour-Ghanaei F, Yousefi Mashhour M, Joukar F, Sedigh M, Bagher-Zadeh AH, Jafarshad R. Prevalence of Helicobacter Pylori Infection among Children in Rasht, Northern Iran. MEJDD. 2009;1(2):84-8. doi: 10.15171/middle\%20east $\% 20$ j\%20di.v1i2.432.

6. Dinis-Ribeiro $M$, Areia $M$, de Vries AC, Marcos-Pinto $R$, Monteiro-Soares $\mathrm{M}$, $\mathrm{O}^{\prime}$ Connor $\mathrm{A}$, et al. Management of precancerous conditions and lesions in the stomach (MAPS): guideline from the European Society of Gastrointestinal Endoscopy (ESGE), European Helicobacter Study Group (EHSG), European Society of Pathology (ESP), and the Sociedade Portuguesa de Endoscopia Digestiva (SPED). Endoscopy. 2019;51(4):365-88. doi: 10.1055/a-0859-1883.

7. Yang HR, Choi HS, Paik JH, Lee HS. Endoscopic and histologic analysis of gastric mucosa-associated lymphoid tissue in children with Helicobacter pylori infection. J Pediatr Gastroenterol Nutr. 2013;57(3):298-304. doi: 10.1097/ MPG.0b013e318298020a.

8. Kim TJ, Lee H, Kang M, Kim JE, Choi YH, Min YW. Helicobacter pylori is associated with dyslipidemia but not with other risk factors of cardiovascular disease. Sci Rep. 2016;6:38015. doi: 10.1038/srep38015.

9. Pourfarzi F, Whelan A, Kaldor J, Malekzadeh R. The role of diet and other environmental factors in the causation of gastric cancer in Iran--a population based study. Int J Cancer. 2009;125(8):1953-60. doi: 10.1002/ijc.24499.

10. Malaty HM, Kumagai T, Tanaka E, Ota H, Kiyosawa K, Graham DY, et al. Evidence from a nine-year birth cohort study in Japan of transmission pathways of Helicobacter pylori infection. J clin Microbiol. 2000;38(5):1971-3. doi: 10.1128/JCM.38.5.19711973.2000.

11. Masjedizadeh AR, Fathizadeh P, Shayesteh AA, Alavinejad P, Hashemi J, Hajiani E. Prevalence of H.pylori Infection and Precancerous Gastric Lesion in Family Relative of Gastric Cancer in South West of Iran. J Gastroenterol Hepatol Res. 2013;2(11):878-82. doi:10.6051/j.issn.22243992.2013.02.380.

12. Shimoyama T. Stool antigen tests for the management of Helicobacter pylori infection. World J Gastroenterol. 2013; 19(45):8188-91. doi: 10.3748/wjg.v19.i45.8188.

13. Malfertheiner P, Megraud F, O'Morain CA, Atherton J, Axon AT, Bazzoli F, et al. Management of Helicobacter pylori infection-the Maastricht IV/Florence Consensus Report. Gut. 2012;61:646-64. doi: 10.1136/gutjnl-2012-302084.

14. Fock KM, Katelaris P, Sugano K, Ang TL, Hunt R, Talley NJ, et al. Second Asia-Pacific Consensus Guidelines for Helicobacter pylori infection. J Gastroenterol Hepatol. 2009;24:1587-600. doi: 10.1111/j.1440-1746.2009.05982.x.

15. Asaka M, Kato M, Takahashi S, Fukuda Y, Sugiyama T, Ota $\mathrm{H}$, et al. Guidelines for the management of Helicobacter pylori infection in Japan: 2009 revised edition. Helicobacter. 2010;15:1-20. doi: 10.1111/j.1523-5378.2009.00738.x.

16. Odaka T, Yamaguchi T, Koyama H, Saisho H, Nomura F. Evaluation of the Helicobacter pylori stool antigen test for monitoring eradication therapy. Am J Gastroenterol. 2002;97:594-9. doi: 10.1111/j.1572-0241.2002.05535.x.

17. Veijola L, Oksanen A, Löfgren T, Sipponen P, Karvonen AL, Rautelin H. Comparison of three stool antigen tests in confirming Helicobacter pylori eradication in adults. Scand J Gastroenterol. 2005;40:395-401. doi: 
$10.1080 / 00365520510012154$.

18. Deguchi R, Matsushima M, Suzuki T, Mine T, Fukuda R, Nishina M. Comparison of a monoclonal with a polyclonal antibody-based enzyme immunoassay stool test in diagnosing Helicobacter pylori infection after eradication therapy. J Gastroenterol. 2009;44:713-6. doi: 10.1007/s00535-0090069-z.

19. Gisbert JP, de la Morena F, Abraira V. Accuracy of monoclonal stool antigen test for the diagnosis of $\mathrm{H}$. pylori infection: a systematic review and meta-analysis. Am J Gastroenterol. 2006;101(8):1921-30. doi:10.1111/j.15720241.2006.00668.x

20. Sykora J, Rowland M. Helicobacter pylori in pediatrics. Helicobacter. 2011;16 Suppl 1:59-64. doi: 10.1111/j.15235378.2011.00882.x.

21. McNulty CA, Lehours P, Megraud F. Diagnosis of Helicobacter pylori Infection. Helicobacter. 2011;16 Suppl 1:10-8. doi: 10.1111/j.1523-5378.2011.00875.x.

22. Raguza D, Machado RS, Ogata SK, Granato CF, Patricio FR, Kawakami E. Validation of a monoclonal stool antigen test for diagnosing Helicobacter pylori infection in young children. J Pediatr Gastroenterol Nutr. 2010;50(4):400-3. doi: 10.1097/ MPG.0b013e3181ac6770.

23. Eusebi LH, Zagari RM, Bazzoli F. Epidemiology of Helicobacter pylori infection. Helicobacter. 2014;19 Suppl 1:1-5. doi: 10.1111/hel.12165.

24. Calvet X, Ramirez Lazaro MJ, Lehours P, Megraud F. Diagnosis and epidemiology of Helicobacter pylori infection. Helicobacter. 2013;18 Suppl 1:5-11. doi: 10.1111/hel.12071.

25. Kimang'a AN, Revathi G, Kariuki S, Sayed S, Devani S. Helicobacter pylori: prevalence and antibiotic susceptibility among Kenyans. S Afr Med J. 2010;100(1):53-7.

26. Mana F, Vandebosch S, Miendje Deyi V, Haentjens P, Urbain D. Prevalence of and risk factors for $\mathrm{H}$. pylori infection in healthy children and young adults in Belgium anno 2010/2011. Acta Gastroenterol Belg. 2013;76(4):381-5.

27. Krueger WS, Hilborn ED, Converse RR, WadeTJ. Environmental risk factors associated with Helicobacter pylori seroprevalence in the United States: a cross-sectional analysis of NHANES data. Epidemiol Infect. 2015;143(12):2520-31. doi: 10.1017/ S0950268814003938.

28. Siavoshi F, Malekzadeh R, Daneshmand M, Ashktorab H. Helicobacter pylori endemic and gastric disease. Dig Dis Sci. 2005;50(11):2075-80. doi: 10.1007/s10620-005-3010-1.
29. Concato J, Peduzzi P, Holford TR, Feinstein AR. The importance of event per variable (EPV) in proportional hazard analysis: I. Background, goals and general strategy. J Clin Epidemiol. 1995;48(12):1495-501. doi: 10.1016/0895-4356(95)00510-2 .

30. Peduzzi P, Concato J, Kemper E, Holford TR, Feinstein AR. A simulation study of the number of events per variable in logistic regression analysis. J Clin Epidemiol. 1996;49(2):1373-9. doi: 10.1016/s0895-4356(96)00236-3.

31. Greenland S, Mansournia MA, Altman DG. Sparse data bias: aproblem hiding in plain sight. BMJ. 2016;352:i1981. doi: 10.1136/bmj.i1981.

32. Baldassarre ME, Monno R, Laforgia N, Fumarola L, Fanelli M, Sgobba C, et al. The source of Helicobacter pylori infection in the neonatal period. J Perinat Med. 2009;37(3):288-92. doi: 10.1515/JPM.2009.045.

33. Stray-Pedersen A, Gaustad P, Stray-Pedersen B, Rognum TO. Detection rate of Helicobacter pylori stool antigen in newborn infants and small children. J Perinat Med. 2007;35(2):155-8. doi: 10.1515/JPM.2007.040.

34. Siavoshi F, Taghikhani A, Malekzadeh R, Sarrafnejad A, Kashanian M, Jamal AS, et al. The role of mother's oral and vaginal yeasts in transmission of Helicobacter pylori to neonates. Arch Iran Med. 2013;16(5):288-94.

35. Torres J, Perez-Perez G, Goodman KJ, Atherton JC, Gold BD, Harris PR, et al. A comprehensive review of the natural history of Helicobacter pylori infection in children. Arch Med Res. 2000;31(5):431-69. doi: 10.1016/s0188-4409(00)00099-0.

36. Bures J, Kopacova M, Koupil I, Seifert B, Skodova Fendrichova M, Spirkova J, et al. Significant decrease in prevalence of Helicobacter pylori in the Czech Republic. World J Gastroenterol. 2012;18(32):4412-8. doi: 10.3748/wjg.v18. i32.4412.

37. Perets TT, Shporn E, Boltin D, Dickman R, Niv Y. Stability of (13) C-Urea Breath Test Samples Over Time in the Diagnosis of Helicobacter pylori. J Clin Lab Anal. 2016;30(3):231-4. doi: 10.1002/jcla.21841.

38. Talebi Bezmin Abadi A. Vaccine against Helicobacter pylori: Inevitable approach. World J Gastroenterol. 2016;22(11):31507. doi: 10.3748/wjg.v22.i11.3150.

39. Talebi Bezmin Abadi A, Lee YY. Chinese Helicobacter pylori vaccine: Solution for an old challenge?. World J Gastrointest Pharmacol Ther. 2016;7(3):412-5. doi: 10.4292/wjgpt. v7.i3.412. 